\title{
Prostacyclin Treatment in Severe Traumatic Brain Injury: A Microdialysis and Outcome Study
}

\author{
Magnus Olivecrona, ${ }^{1}$ Marie Rodling-Wahlström, ${ }^{2}$ Silvana Naredi, ${ }^{2}$ and Lars-Owe D. Koskinen ${ }^{1}$
}

\begin{abstract}
Prostacyclin $\left(\mathrm{PGI}_{2}\right)$ is a potent vasodilator, inhibitor of leukocyte adhesion, and platelet aggregation. In trauma the balance between $\mathrm{PGI}_{2}$ and thromboxane $\mathrm{A}_{2}\left(\mathrm{TXA}_{2}\right)$ is shifted towards $\mathrm{TXA}_{2}$. Externally provided $\mathrm{PGI}_{2}$ would, from a theoretical and experimental point of view, improve the microcirculation in injured brain tissue. This study is a prospective consecutive double-blinded randomized study on the effect of $\mathrm{PGI}_{2}$ versus placebo in severe traumatic brain injury (sTBI). All patients with sTBI were eligible. Inclusion criteria: verified sTBI, Glasgow Coma Score (GCS) at intubation and sedation of $\leq 8$, age 15-70 years, a first-recorded cerebral perfusion pressure (CPP) of $\geq 10 \mathrm{~mm} \mathrm{Hg}$, and arrival within $24 \mathrm{~h}$ of trauma. All subjects received an intracranial pressure (ICP) measuring device, bilateral intracerebral microdialysis catheters, and a microdialysis catheter in the abdominal subcutaneous adipose tissue. Subjects were treated according to an ICP-targeted therapy based on the Lund concept. 48 patients (mean age of 35.5 years and a median GCS of 6 [3-8]) were included. We found no significant effect of prostacyclin (epoprostenol, Flolan) on either the lactate-pyruvate ratio $(\mathrm{L} / \mathrm{P})$ at $24 \mathrm{~h}$ or the brain glucose levels. There was no significant difference in clinical outcome between the two groups. The median Glasgow Outcome Score (GOS) at 3 months was 4, and mortality was 12.5\%. The favorable outcome (GOS 4-5) was $52 \%$. The initial $\mathrm{L} / \mathrm{P}$ did not prognosticate for outcome. Thus our results indicate that there is no effect of $\mathrm{PGI}_{2}$ at a dose of $0.5 \mathrm{ng} / \mathrm{kg} / \mathrm{min}$ on brain L/P, brain glucose levels, or outcome at 3 months.
\end{abstract}

Key words: lactate-pyruvate ratio; microdialysis; prostacyclin; severe traumatic brain injury

\section{Introduction}

$\mathbf{S}_{\mathrm{n}}^{\mathrm{s}}$ EVERE TRAUMATIC BRAIN INJURY (STBI) is a major cause of morbidity and mortality in the population, especially in younger age groups. Since the introduction of an intracranial pressure (ICP) guided treatment protocol based on the Lund concept for sTBI (Asgeirsson et al., 1994; Grande et al., 1997, 2002) in our department we have reported favourable outcome, GOS $4-5$, in the range of 60 to $70 \%$ and a mortality in the range of 10 to $15 \%$ (Naredi et al., 2001; Wahlstrom et al., 2005; Olivecrona et al., 2007).

$\mathrm{PGI}_{2}$ produced in the vascular endothelium is a potent vasodilator and inhibitor of leukocyte activation and adhesion to the vascular endothelium and platelet aggregation (Moncada et al., 1976; Moncada and Amezcua, 1979; Moncada and Vane, 1979b). The equilibrium between $\mathrm{PGI}_{2}$ and $\mathrm{TXA}_{2}$ seen in the healthy subject is in the traumatized subject altered and shifted towards TXA 2 (Gryglewski et al., 1978; Moncada and Amezcua, 1979). This relative decrease in $\mathrm{PGI}_{2}$ levels would lead to decreased vasodilation, increased leu- kocyte adhesion and platelet aggregation, and thus an impaired microcirculation. Beneficial effects of $\mathrm{PGI}_{2}$ in experimental models of traumatic brain injury and microvascular permeability have been reported (Moller and Grande, 1997, 1999a, 1999b; Bentzer et al., 1999, 2001a, 2001b). In a study of experimental brain trauma, cerebral cortical blood flow and cortical lesion volume were studied in mice with and without the prostacylin receptor gene $\left(\mathrm{IP}^{+/+}\right.$and $\left.\mathrm{IP}^{-/-}\right)$. The study showed that the blood flow returned earlier to normal values and that the lesion volume was less in the $\mathrm{IP}^{+/+}$mice (Lundblad et al., 2008). Low-dose $\mathrm{PGI}_{2}$ given to five subjects with sTBI seemed to have some effects on energy metabolism related substances measured by brain microdialysis (Grande et al., 2000). We showed in 2001 (Naredi et al.) that epoprostenol given to subjects with sTBI did not induce side effects and had a tendency to improve outcome.

The present study is a prospective consecutive doubleblinded randomized study of the effect of epoprostenol versus placebo in subjects with STBI conducted at a Level 1 trauma center. The specific aim of the study was to establish whether

${ }^{1}$ Department of Neurosurgery, ${ }^{2}$ Department of Anaesthesiology, Umeå University Hospital, Umeå, Sweden. 
the treatment with low-dose epoprostenol would reduce a $\mathrm{L} / \mathrm{P}$ as measured by cerebral microdialysis after $24 \mathrm{~h}$ of treatment. The $\mathrm{L} / \mathrm{P}$ is considered the most reliable marker for the redox state of the brain (Granholm and Siesjo, 1969; Persson and Hillered, 1992; Enblad et al., 1996). Secondly, the changes in microdialysis parameters over time in the epoprostenol and placebo groups were studied. Thirdly, the aim was to compare outcome, as measured by GOS, between the two treatment groups at 3 months, and fourthly, to study if the initial L/P can prognosticate outcome estimated as GOS at 3 months.

\section{Material and Methods}

\section{Subjects}

All subjects with sTBI admitted to the department between January 1, 2002 and December 31, 2005 were eligible to be recruited into the study. The inclusion criteria were as follows: verified severe traumatic head injury, GCS at intubation and sedation of 8 or less, age between 15 and 70 years, a firstmeasured CPP of $10 \mathrm{~mm} \mathrm{Hg}$ or more, and arrival in our department within $24 \mathrm{~h}$ of trauma. Exclusion criteria were: pregnant or lactating woman, known bleeding diathesis, known allergy to epoprostenol, and penetrating head injury. Thus, the study allowed for inclusion of subjects with GCS 3 and dilated fixed pupils as long as the initial CPP was $10 \mathrm{~mm}$ $\mathrm{Hg}$ or above.

The treating physician enrolled subjects fulfilling the criteria into the study and a written informed consent was obtained from their relatives. At the follow-up examination the subjects were asked to accept the inclusion into the study and to the follow-up. The subject had to be in need of cerebral intensive care for more than $72 \mathrm{~h}$. Subjects who were extubated and or discharged alive from the ICU within this time were excluded from the study as their brain injuries were not regarded as severe enough. All subjects dead within the first 3 months of inclusion to the study were regarded as due to the sTBI and thus as mortality in the study.

\section{Monitoring}

Intracranial pressure. All subjects received an intraparenchymal ICP measuring device (Codman MicroSensor, Johnson \& Johnson Professional, Raynham, MA). The MicroSensor was placed through a burr hole preferable right frontal, approximately at the point of Kocher. The MicroSensor was used for ICP monitoring even if the subject later during the treatment received a ventriculostomy. This ICP sensor has been shown to be reliable with very low drift under clinical conditions (Koskinen and Olivecrona, 2005). If a ventriculostomy was placed, it was mainly used as drainage to treat ICP elevations. The drain was kept closed and opened only for drainage of minimal amounts of fluid.

Other physiological parameters. Arterial blood pressure was invasively continuously monitored with reference level at heart level. Systolic and diastolic blood pressures were registered and mean arterial blood pressure (MAP) and CPP were calculated by the monitoring equipment (Marquette Solar, General Electric Medical Systems, Milwaukee, WI). As all patients were positioned flat, the reference point for ICP and MAP is at the same level, resulting in a negligible hydrostatic difference between the measuring sites. Thus no correction is needed for the CPP calculation. Further physiological parameters were monitored continuously.

\section{Microdialysis}

Two microdialysis catheters with gold tip were inserted into the brain (CMA 70, CMA Microdialysis, Solna, Sweden). They were placed in a standardized fashion frontally on each side approximately at the point of Kocher. The catheter placed in the most injured hemisphere, as judged from the primary CT scans, was designated A, and the other catheter designated B. A third microdialysis catheter (CMA 60, CMA Microdialysis) was placed in the subcutaneous adipose tissue of the upper part of the abdomen and designated $\mathrm{C}$. The CMA 106 or 107 microdialysis pumps (CMA Microdialysis) were used and all three catheters perfused at a flow rate of $0.3 \mu \mathrm{L} / \mathrm{min}$. The "perfusion fluid CNS" (CMA Microdialysis) was used for the brain catheters, and "perfusion fluid $\mathrm{T} 1$ " (CMA Microdialysis) was used for the subcutaneous catheter. The first dialysate was discharged. The sampling was started (0.5-2.5 h after the start of the microdialysis) and the sampling time for each sample was $2 \mathrm{~h}$. The first sample of microdialysis was collected as 0-sample (zero sample, baseline). The vials were stored in a freezer $\left(-20^{\circ} \mathrm{C}\right)$ for not more than $24 \mathrm{~h}$ and then frozen to $-70^{\circ} \mathrm{C}$, if not directly analyzed. The microdialysis samples were analyzed as soon as possible using a CMA 600 analyzer (CMA Microdialysis). Absolute values are reported for glucose levels and for $\mathrm{L} / \mathrm{P}$ calculations.

\section{Injury severity}

For describing the severity of the injuries, ISS (Injury Severity Score) was used. As a measure of severity of illness, the subjects were scored according to APACHE II (Acute Physiology and Chronic Health Evaluation II).

\section{Test drug}

Epoprostenol (Flolan, GlaxoSmithKline, Brentford, United Kingdom) was used as active and saline as placebo test drug. The hospital pharmacy prepared the active drug and placebo in individually identifiable and numbered containers. The investigators, the treating physicians, and the ICU nurses, as well as the subjects and their relatives, were blinded through the follow-up time. The test drug was started at the same time as the microdialysis 0 sample was changed and given at an infusion rate corresponding to a dose of $0.5 \mathrm{ng} / \mathrm{kg} / \mathrm{min}$ for $72 \mathrm{~h}$. The test drug was then tapered over $24 \mathrm{~h}$.

\section{Treatment}

An ICP-targeted treatment protocol was used. This has thoroughly been described elsewhere (Olivecrona et al., 2007), and is based on the Lund concept (Asgeirsson et al., 1994; Grande et al., 1997, 2002). In short, all subjects were continuously sedated, using midazolam and fentanyl, and artificially ventilated $\left(\mathrm{P}_{\mathrm{a}} \mathrm{O}_{2} \geq 12 \mathrm{kPa} ; \mathrm{P}_{\mathrm{a}} \mathrm{CO}_{2} \quad 4.5-5.5 \mathrm{kPa}\right)$. Normovolemia and normal colloid osmotic pressure were aggressively maintained, using infusion of packed red blood cells, albumin, Ringer's acetate, and glucose solutions. A neutral fluid balance was targeted, if necessary with help of furosemide. In order to normalize the blood pressure, after the establishment of normovolemia, and so to reduce the capillary 
hydrostatic pressure and the general level of stress in the subjects, continuous infusions of clonidine and metoprolol were used. Further treatments steps to control the ICP were low-dose thiopental infusion, aiming at continuous delta activity on the EEG; ventriculostomy for drainage of CSF; and uni- or bilateral craniectomy. The subjects were all treated in the supine position without head elevation.

\section{Randomization}

Subjects were randomized to epoprostenol or placebo treatment by means of the random number method. With an effect size of 0.4 and a power of 0.8 , the required total sample size needed was calculated to be 50 .

\section{Outcome}

The subjects were followed-up at 3 months after injury. The interview followed the guidelines of the extended GOS and was performed by independent staff. The outcome is reported as GOS.

\section{Data storage and statistics}

All the collected data were digitally stored. Physiological and respiratory parameters from the ICU system (Marquette Solar, General Electric Medical Systems) were stored on a computer using the LABpilot software (CMA Microdialysis). The data were simultaneously stored in the patient's case file in the ICU system (Picis, Inc., Wakefield, MA). The microdialysis data were transferred from the CMA 600 analyzer to a personal computer and further processed with the LABpilot software. Statistical analysis and further processing of the data were performed with commercial statistical packages. Every case file was scrutinized for outliers due to, for example, calibration periods and mechanical disturbances. Further, the correlation in time of the sampling values was controlled.

Results are reported as means \pm standard error of the mean (SEM) for continuous variables and in cases of discrete variables as median and range. When applicable, two-sided paired or un-paired Student's $t$-test was used for continuous data. Wilcoxon rank sum test was used for discrete variables. $\chi^{2}$-test was applied for proportions. Correlations were used as indicated, and Receiver Operator Characteristics (ROC) analyses were used to test predictability. A $p$ of $\leq 0.05$ was considered statistically significant.

\section{Ethics and approval}

The study was approved (Dnr 00-175) by the local ethics committee at Umeå University Hospital. The study was classified as a drug study and appropriate approval was given by Läkemedlesverket (Medical Products Agency, 151:633/01).

\section{Results}

Forty-nine subjects were randomized into the study. The relatives of one patient refused participation after randomization. Thus, 48 subjects (17 females, 31 males) participated in the study. Figure 1 depicts the progress through the study. In the epoprostenol group (PG-G) 23 subjects were included and in the placebo group (Plac-G) 25 subjects. The mean age was $35.5 \pm 2.2$ years. The median GCS on intubation and sedation was 6 (3-8). Figure 2 shows the GCS distribution. There were no statistically significant differences in age, gender, GCS, ISS, or APACHE II between the two groups (unpaired Student's $t$-test [age], $\chi^{2}$ test [gender], and Wilcoxon rank sum test) (Table 1). The ISS and the APACHE II indicate that the subjects were severely traumatized. Thirty-three $(68.7 \%)$ were multi-traumatized. There was no significant difference in the time from accident until implantation of microdialysis catheters between the two groups (unpaired Student's $t$-test, see Table 1).

In Figure 3, the ICP, MAP, and CPP over time are depicted. There was no statistically significant difference between the two groups. It is clear that both ICP and CPP were well within the preset treatment goals. An ICP of above $20 \mathrm{~mm} \mathrm{Hg}$ was recorded in less than $3 \%$ of all the registered ICP values during the first $120 \mathrm{~h}$ of treatment (once a minute). The same figure was found for CPP values lower than $50 \mathrm{~mm} \mathrm{Hg}$. In Figure 4, the ICP, MAP and CPP between survivors and deceased subjects are illustrated. ICP in the survivors was significantly lower than that in the deceased subjects.

The initial L/P was clearly elevated as compared to supposed normal values. We found a statistically significant reduction in $\mathrm{L} / \mathrm{P}$ in the A catheter comparing the 0-sample with the sample after $24 \mathrm{~h}$ of treatment $(65.9 \pm 7.3$ and $41.8 \pm 5.1$, $p \leq 0.01$, paired Student's $t$-test). Similar results were found in the B catheter even though the difference was not statistically significant $(63.9 \pm 13.4$ and $37.3 \pm 2.8, p=0.09$; paired Student's $t$-test). In the B catheter there was one subject with an abnormally high baseline $\mathrm{L} / \mathrm{P}$ of 470.6 and a $\mathrm{L} / \mathrm{P}$ of 63.8 at $24 \mathrm{~h}$. Excluding this subject, the baseline L/P in the B catheter would be $52.3 \pm 6.9$, and after $24 \mathrm{~h}$ of treatment $36.7 \pm 2.8$ $(p \leq 0.02)$. Table 2 illustrates the $\mathrm{L} / \mathrm{P}$ in the 0 -sample and at $24 \mathrm{~h}$ of treatment for both groups and divided by the different catheters. There was no statistically significant difference between the PG-G and Plac-G comparing the L/P at $24 \mathrm{~h}$ of treatment or comparing the relative decrease in the $\mathrm{L} / \mathrm{P}$. Figure $5 \mathrm{~A}$ shows the temporal profile of $\mathrm{L} / \mathrm{P}$ in the $\mathrm{A}$ and $\mathrm{B}$ catheters for the whole material, and in Figure 5B the corresponding profile in the treatment groups. There was no statistical significant difference in the temporal profile of the $\mathrm{L} / \mathrm{P}$ comparing catheters $\mathrm{A}$ and $\mathrm{B}$ or between the groups. The $\mathrm{L} / \mathrm{P}$ was in both of the catheters and in both the treatment groups clearly elevated at the start of the treatment and did gradually decrease over time. We did not find any significant difference between the treatment groups at $24 \mathrm{~h}$, even if we only considered the subjects with an initial $\mathrm{L} / \mathrm{P}$ of $>40$.

The initial L/P (A catheter) differs between survivors and non-survivors, $62.5 \pm 8.2$ and $86.2 \pm 18.6$, respectively. Due to great variation in the $\mathrm{L} / \mathrm{P}$ in the deceased subjects, the difference was not statistically significant. If postulating that the subjects deceased at 3 months should have a higher $\mathrm{L} / \mathrm{P}$ than the survivors due to a more severe brain injury, one could apply a one-sided un-paired Student's $t$-test. In this situation the difference between 0 -samples $\mathrm{L} / \mathrm{P}$ in survivors and deceased is statistically significant at $p<0.05$. Furthermore, in ten subjects, the 0 -sample L/P exceeded 100 in one or both of the microdialysis catheters (mean 194.2 \pm 37.2 ).

The cerebral glucose levels in the 0 -sample and at $24 \mathrm{~h}$ of treatment did not show a statistically significant difference. They were in the A catheter $2.0 \pm 0.3 \mathrm{mmol} / \mathrm{L}$ and $1.9 \pm 0.2$ $\mathrm{mmol} / \mathrm{L}$, respectively, and in the B catheter $2.0 \pm 0.2 \mathrm{mmol} / \mathrm{L}$ and $1.9 \pm 0.2 \mathrm{mmol} / \mathrm{L}$, respectively. In Table 3 the glucose levels in both catheters separated by treatment at baseline and 


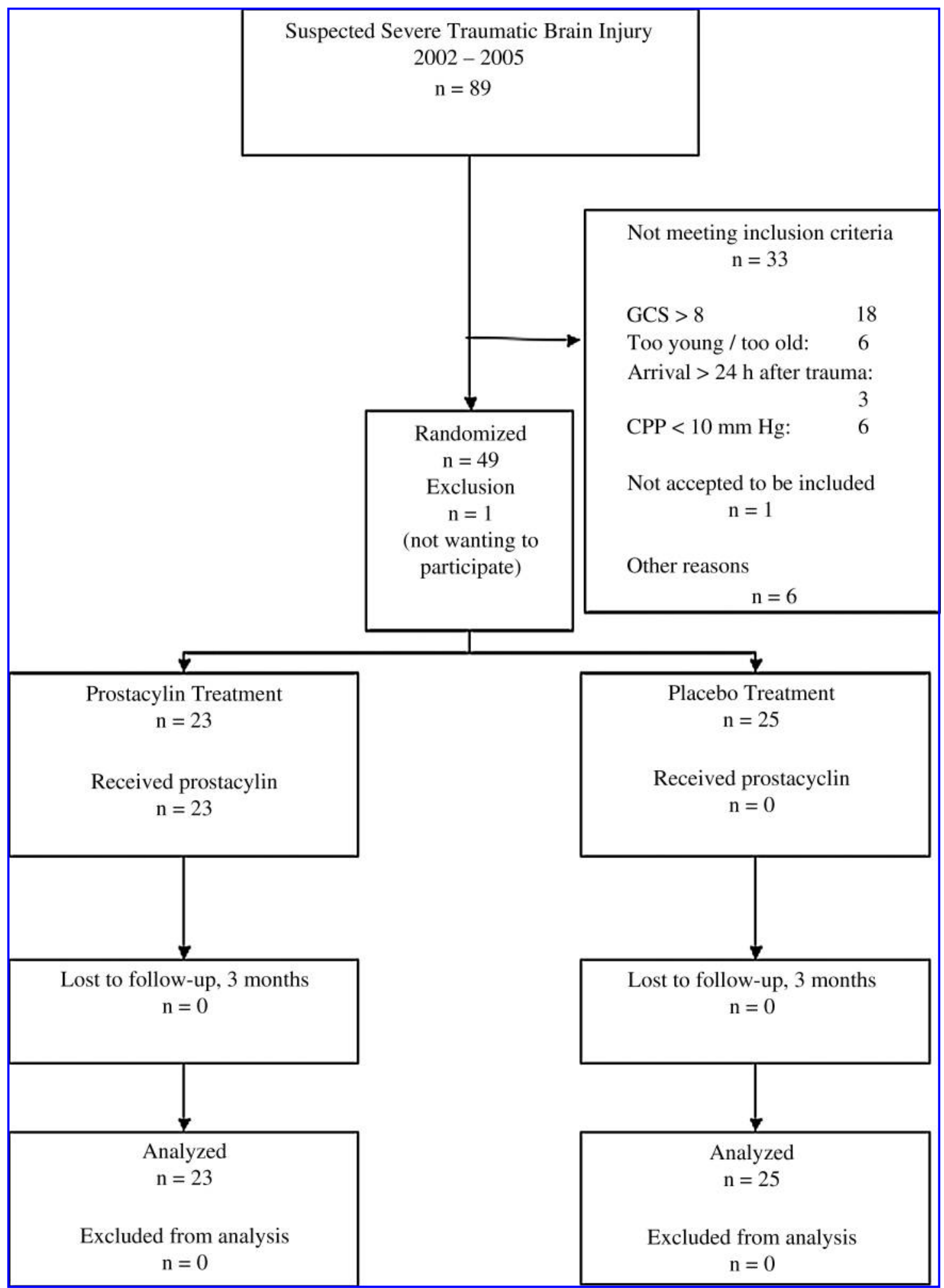

FIG. 1. Flow through the study.

at $24 \mathrm{~h}$ of treatment are depicted. There was a tendency toward a gradual decrease in the CNS glucose level over time (Fig. 6). There was no significant difference in glucose levels between the PG-G and Plac-G. The baseline subcutaneous glucose concentration was $3.6 \pm 0.4 \mathrm{mmol} / \mathrm{L}$ and after $24 \mathrm{~h}$ the value was $4.9 \pm 0.3 \mathrm{mmol} / \mathrm{L} \quad(p<0.0001$ paired Student's $t$-test). As shown in Figure 6, there was a slight increase in the subcutaneous glucose concentration during the first few hours, which levelled out at a stable concentration. The ratio between the glucose concentration in the A catheter and the 


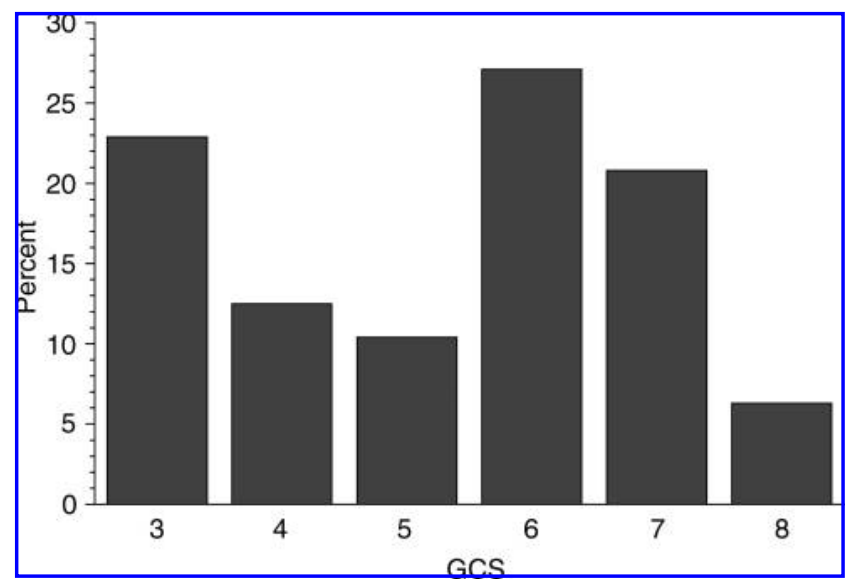

FIG. 2. Distribution of GCS in the total material on sedation and intubation.

$\mathrm{C}$ catheter is constant over time (Fig. 6). The same result was seen when the ratio between the $B$ and $C$ catheter was calculated.

At the 3-month follow-up, the favorable outcome (GOS 45) was $52 \%$ and the mortality $12.5 \%$. Figure 7 depicts the GOS distribution. There was no statistically significant difference in outcome between the treatment groups $\left(\chi^{2}\right.$-test). Even if the outcome is divided into in three groups, favorable (GOS 4-5), unfavorable (GOS 2-3), and death (GOS 1), no statistically significant difference can be proven between the treatment groups $\left(\chi^{2}\right.$-test). If excluding subjects with an initial GCS of 3 and/or bilateral dilated and fixed pupils, the favorable outcome would be $61 \%$ and the mortality $0 \%$. Furthermore, of the deceased subjects, only two died during the ICU time. An uncontrollable high ICP was the direct cause of death in these subjects. They both presented with GCS of 3 and fixed dilated pupils. One of the subjects had had a circulatory arrest at the scene of the accident. The causes of death found among the subjects deceased outside the ICU were pulmonary artery embolism, pneumonia, and the decision to stop further active treatment (GOS 2).
Figure 8 depicts the initial $\mathrm{L} / \mathrm{P}$ in the $\mathrm{A}$ catheter in relation to the GOS at 3 months. In neither the A nor the B catheter was there a statistically significant correlation between $\mathrm{L} / \mathrm{P}$ in the 0 -samples and GOS at 3 months nor the dichotomized GOS at 3 months (GOS 4-5 and GOS 1-3). ROC curve analysis showed no useable predictive value of the 0 -sample $\mathrm{L} / \mathrm{P}$ (A catheter) for dichotomized GOS (area under the curve 0.4867). However, when using deceased and alive in the dichotomization, the area under the curve was 0.701 (95\% CI 0.556-0.835) and a L/P cut-off level of 110 (sensitivity 60\%, specificity $87.5 \%$ ). If the aim would be to use the result of the first sample $\mathrm{L} / \mathrm{P}$ for prediction whether to treat or not, that is, to predict death due to the sTBI, the cut-off value would be 137. This analysis is based on the presumption that the test has to have a specificity of $95 \%$; one of 20 subjects that would have been salvageable were left to die. The sensitivity of the test would then be $20 \%$. Similar results were found when analyzing the B catheter.

\section{Complications}

No complications related to the test drug were observed. There were no bleeding complications due to the insertion of either the ICP sensor or the microdialysis catheters. Although leakage of CSF around the catheters occasionally was seen, no infections, superficial or deep, were identified.

\section{Discussion}

The primary hypothesis of the study was that supplemental treatment with epoprostenol in the dosage of $0.5 \mathrm{ng} / \mathrm{kg} / \mathrm{min}$ would significantly reduce the L/P compared with the placebo group at $24 \mathrm{~h}$ of treatment. This was not met and thus we have to accept the 0-hypothesis that there is no difference between the two groups.

$\mathrm{PGI}_{2}$ is synthesized in the vascular endothelium. $\mathrm{PGI}_{2}$ affects the microvascular permeability, inhibits platelet and leukocyte aggregation, and has vasodilating properties (Moncada and Vane, 1979a, 1979b). Further PGI $_{2}$ has been shown to decrease leukocyte activation and adhesion to vascular endothelium, and thus possess anti-inflammatory

Table 1. Basal Data, Gender, Age, GCS, Injury Severity, Treatment Times, and GOS at 3 Months

\begin{tabular}{|c|c|c|c|}
\hline & All $\mathrm{n}=48$ & $\begin{array}{l}\text { Prostacyclin } \\
\text { group } \mathrm{n}=23\end{array}$ & $\begin{array}{c}\text { Placebo } \\
\text { group } \mathrm{n}=25\end{array}$ \\
\hline Mean age $\pm S E M$ & $35.5 \pm 2.2$ & $35.8 \pm 3.6$ & $35.2 \pm 2.6$ \\
\hline \multicolumn{4}{|l|}{ GCS } \\
\hline Median (range) & $6(3-8)$ & $5(3-8)$ & $6(3-8)$ \\
\hline Mean \pm SEM & $5.3 \pm 0.2$ & $5.1 \pm 0.3$ & $5.5 \pm 0.4$ \\
\hline \multicolumn{4}{|l|}{ ISS } \\
\hline Median (range) & $29(9-50)$ & $29(9-50)$ & $29(9-43)$ \\
\hline Mean $\pm S E M$ & $28.8 \pm 1.4$ & $29.7 \pm 2.0$ & $28.0 \pm 2.0$ \\
\hline \multicolumn{4}{|l|}{ APACHE II } \\
\hline Median (range) & $20.5(12-32)$ & $20.0(12-29)$ & $21.0(14-32)$ \\
\hline Mean \pm SEM & $20.8 \pm 0.7$ & $20.6 \pm 1.1$ & $21.0 \pm 1.0$ \\
\hline \multicolumn{4}{|c|}{ Time from accident until admission } \\
\hline Mean \pm SEM (hours) & $6.2 \pm 0.7$ & $6.5 \pm 1.2$ & $6.0 \pm 0.8$ \\
\hline \multicolumn{4}{|c|}{ Time from accident until implantation of catheters } \\
\hline Mean \pm SEM (hours) & $12.2 \pm 0.7$ & $12.8 \pm 1.1$ & $11.6 \pm 0.9$ \\
\hline \multicolumn{4}{|l|}{ GOS 3 months } \\
\hline Median (range) & $4(1-5)$ & $4(1-5)$ & $3(1-5)$ \\
\hline Mean \pm SEM & $3.5 \pm 3.2$ & $3.7 \pm 0.2$ & $3.4 \pm 0.3$ \\
\hline
\end{tabular}




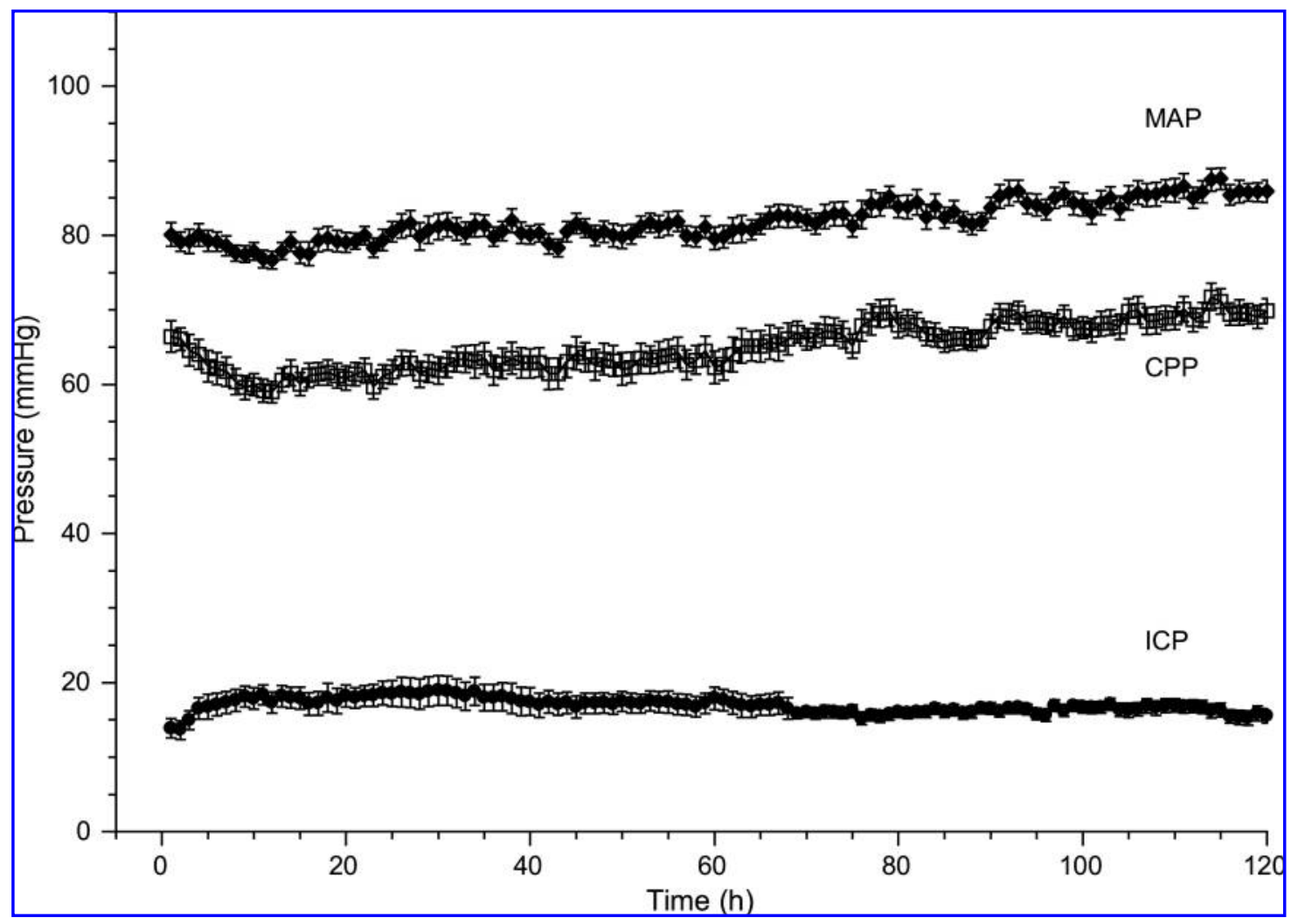

FIG. 3. Mean arterial blood pressure (MAP), cerebral perfusion pressure (CPP), intracranial pressure (ICP) over time in the total material. Values are mean \pm sem.

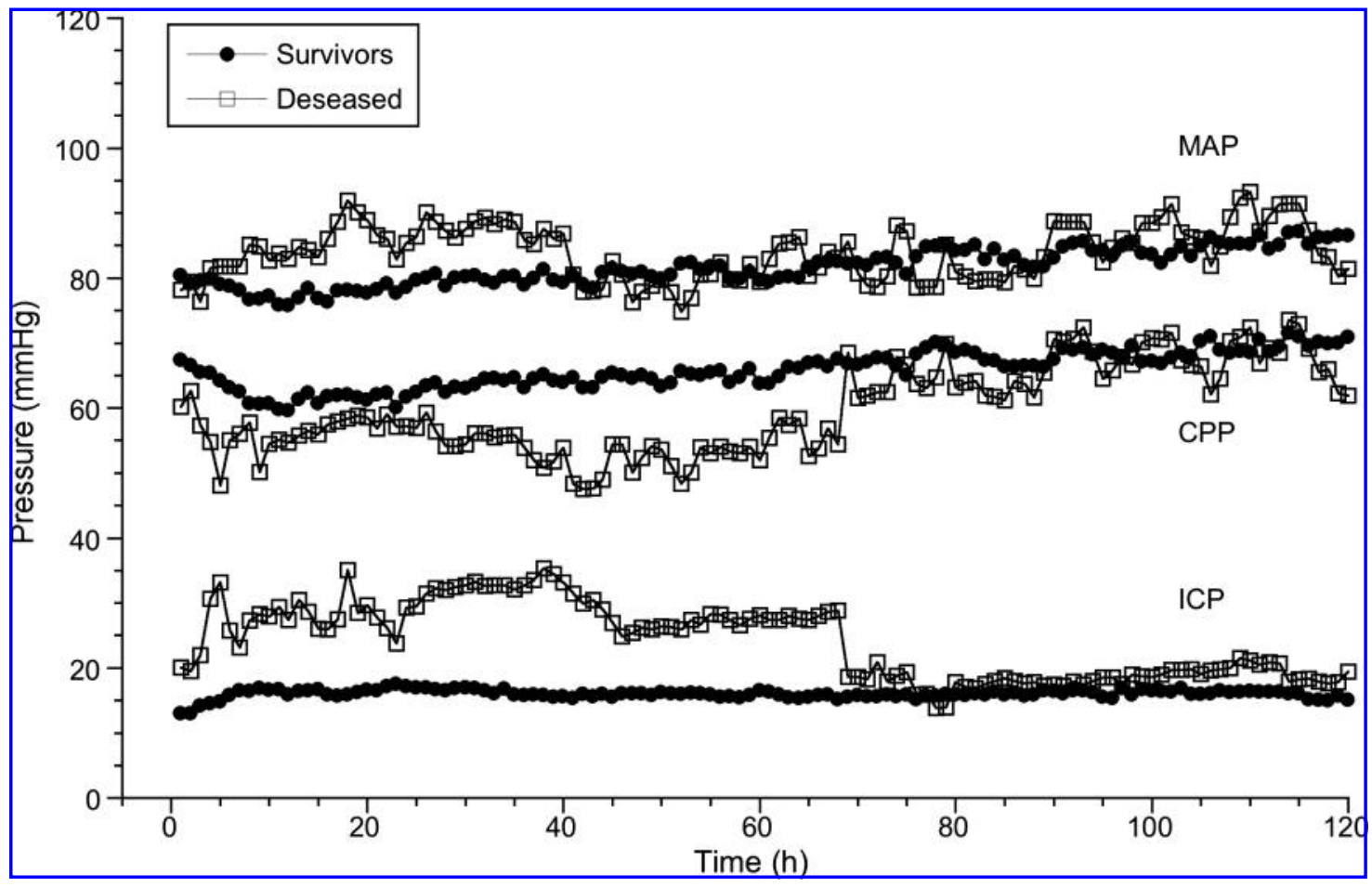

FIG. 4. Mean arterial blood pressure (MAP), cerebral perfusion pressure (CPP), intracranial pressure (ICP) over time in survivors and deceased at 3 months. Values are mean. 
Table 2. L/P in 0-sample and After 24 h of Treatment with Test Drug

\begin{tabular}{|c|c|c|c|c|c|}
\hline \multirow[b]{2}{*}{ Time } & \multicolumn{2}{|c|}{ Prostacyclin group $(\mathrm{n}=23)$} & \multicolumn{2}{|c|}{ Placebo group $(\mathrm{n}=25)$} & \multirow[b]{2}{*}{ Significance } \\
\hline & A catheter & $B$ catheter & A catheter & $B$ catheter & \\
\hline $\begin{array}{l}\text { 0-sample } \\
\quad \text { Mean } \pm \text { SEM }\end{array}$ & $61.9 \pm 8.1$ & $82.1 \pm 28.8$ & $69.6 \pm 12.0$ & $49.3 \pm 6.7$ & $\begin{array}{l}\text { A to A n.s. } \\
\text { B to B n.s. }\end{array}$ \\
\hline $\begin{array}{l}\text { 24h } \\
\quad \text { Mean } \pm \text { SEM }\end{array}$ & $43.1 \pm 5.0$ & $38.7 \pm 3.9$ & $49.7 \pm 11.0$ & $36.2 \pm 3.9$ & $\begin{array}{l}\text { A to A n.s. } \\
\text { B to B n.s. }\end{array}$ \\
\hline Significance & $p<0.005$ & n.s. & n.s. & n.s. & \\
\hline
\end{tabular}

A catheter brain (worse side); B catheter brain (better side); n.s., non-significant (unpaired Student's t-test between groups, paired Student's $t$-test within groups).

properties (Jones and Hurley, 1984; Erlansson et al., 1991). $\mathrm{PGI}_{2}$ has also been shown to reduce an increased microvascular permeability caused by inflammation (Morel et al., 1990). The reduction of permeability positively affects the injured blood brain barrier, making it less permeable to fluids and macromolecules and thus decreasing the risk for extracellular edema (Mizuno-Yagyu et al., 1987; Blebea et al., 1990; Jahr and Grande, 1996). There is experimental and clinical evidence that $\mathrm{PGI}_{2}$ may reduce vasospasm in nontraumatic subarachnoid hemorrhage (SAH) (Boullin et al., 1979; Brandt et al., 1981). We have shown that nimodipine resistant vasospasm in aneurysmal SAH can be reduced by infusion of lowdose epoprostenol (Koskinen et al., 2009). TXA 2 is, on the other hand, a powerful vasoconstrictor and promoter of platelet aggregation (Moncada et al., 1976). An imbalance of $\mathrm{PGI}_{2}$ and $\mathrm{TXA}_{2}$ in the injured brain may result in vasoconstriction, and microembolism and thus impaired microcirculation. The imbalance may also cause vasospasm (Seifert et al., 1987).The endogenous normal production of $\mathrm{PGI}_{2}$ is estimated to be in the range of 0.08 to $0.1 \mathrm{ng} / \mathrm{kg} / \mathrm{min}$ (Lewis and Dollery, 1983; Ritter et al., 1983; Davies and Hagen, 1993). The synthesis of $\mathrm{PGI}_{2}$ and $\mathrm{TXA}_{2}$ is altered immediately after trauma, and thus the balance between the two substances is dislocated toward the effect of $\mathrm{TXA}_{2}$. A relative ischemia in the injured brain would be the consequences of such an impairment of the microcirculation. Thus, from a theoretical and experimental point of view, $\mathrm{PGI}_{2}$ can have beneficial effects in conditions with a compromised microcirculation.

We report a mean ICP over time in this study of below $20 \mathrm{~mm} \mathrm{Hg}$ and a mean CPP of around $60 \mathrm{~mm} \mathrm{Hg}$. This shows that we have managed to follow the intentions of the treatment protocol-ICP below $20 \mathrm{~mm} \mathrm{Hg}$ and CPP not below $50 \mathrm{~mm} \mathrm{Hg}$. There have been discussions about whether this relatively low accepted CPP would lead to an increase of secondary brain injuries and thus a worse outcome (Andrews et al., 2002; Clifton et al., 2002). The initially decreasing and then stable and low L/P and stable brain glucose levels would indicate that the accepted CPP level does not give rise to ischemia defined as a pathological L/P. This observation is also in accordance with the recommendations in the guidelines for treatment of sTBI from the Brain Trauma Foundation (2007) where a CPP of $50-70 \mathrm{~mm} \mathrm{Hg}$ is acceptable. The high number of favorable outcomes and low mortality indicate that an ICP targeted therapy based on the Lund concept contributes to avoidance of secondary injuries.

The elevation of the $\mathrm{L} / \mathrm{P}$ in the brain is considered a reliable indicator of cerebral ischemia (Granholm and Siesjo, 1969; Persson and Hillered, 1992; Enblad et al., 1996). The $\mathrm{L} / \mathrm{P}$ is elevated, at least in the early course of sTBI, as an indicator of brain injury and a compromised microcirculation. One can speculate that the amount of $\mathrm{PGI}_{2}$ infused in the present study was too low to affect the $\mathrm{L} / \mathrm{P}$. However, the $\mathrm{PGI}_{2}$ dose administered $(0.5 \mathrm{ng} / \mathrm{kg} / \mathrm{min})$ was close to the estimated endogenous production of $\mathrm{PGI}_{2}$. The used dose of $\mathrm{PGI}_{2}$ was also in correspondence with the doses (0.5$1 \mathrm{ng} / \mathrm{kg} / \mathrm{min}$ ) used by Grande and colleagues (2000), eliciting some effects on energy metabolism related substances in five patients treated for sTBI. Our present findings do not support the findings by Grande et al. (2000). However, that study was a pilot and there was no control group. Thus, it is impossible to judge whether the effects were elicited by epoprostenol or were a part of the natural course of the brain trauma. We have earlier published a pilot and safety study using $\mathrm{PGI}_{2}$ at a dose of $0.5 \mathrm{ng} / \mathrm{kg} / \mathrm{min}$ (Naredi et al., 2001). The choice of dose thus relied on the report from Grande and colleagues and our own safety study.

The $\mathrm{L} / \mathrm{P}$ in the total material and in the two groups follows each other closely over time. As an indicator of a severe brain injury, the L/P was elevated to values well above the presumed normal value of 20 (Reinstrup et al., 2000; Schulz et al., 2000). The $\mathrm{L} / \mathrm{P}$ decreased over time and had significantly decreased at $24 \mathrm{~h}$ of treatment without significant difference between the PG-G and Plac-G. Still at $120 \mathrm{~h}$ after start of treatment, the $\mathrm{L} / \mathrm{P}$ was clearly higher than the above stated normal value. The changes we report in $\mathrm{L} / \mathrm{P}$ over time in subjects with sTBI are well in accordance with the findings of several other authors, that is, a starting point in high values and a decrease towards normal levels over time (Persson and Hillered, 1992; Stahl et al., 2001b). The initial elevation of the $\mathrm{L} / \mathrm{P}$ would suggest a relative lack of oxygen compromising the mitochondrial function with an effect on the redox-state. The $\mathrm{L} / \mathrm{P}$ are elevated, but in the majority of the subjects far from the values attributed to a truly ischemic brain, when values in the hundreds would be expected (Schulz et al., 2000). However, the normal value is derived from a low number of subjects (Reinstrup et al., $\mathrm{n}=5$; Schulz et al., $\mathrm{n}=14$ ) and have been questioned (Vespa et al., 2005). Our results show that the L/P levelled out around 40 . Whether this actually is the normal value or not cannot be judged from our series. There are indications from other authors that a cut-off level of L/P of approximately 40 is more appropriate (Vespa et al., 2005, 2007). Furthermore, a publication from our department on microdialysis data in awake patients suffering from idiopathic normal pressure hydrocephalus reported a L/P of about 40 (Agren-Wilsson et al., 2005). We therefore consider that a $\mathrm{L} / \mathrm{P}$ in the range of 40 may be normal. Based on this assumption that a $\mathrm{L} / \mathrm{P}>40$ is abnormal, and only considering subjects with an initial $\mathrm{L} / \mathrm{P}$ exceeding this 


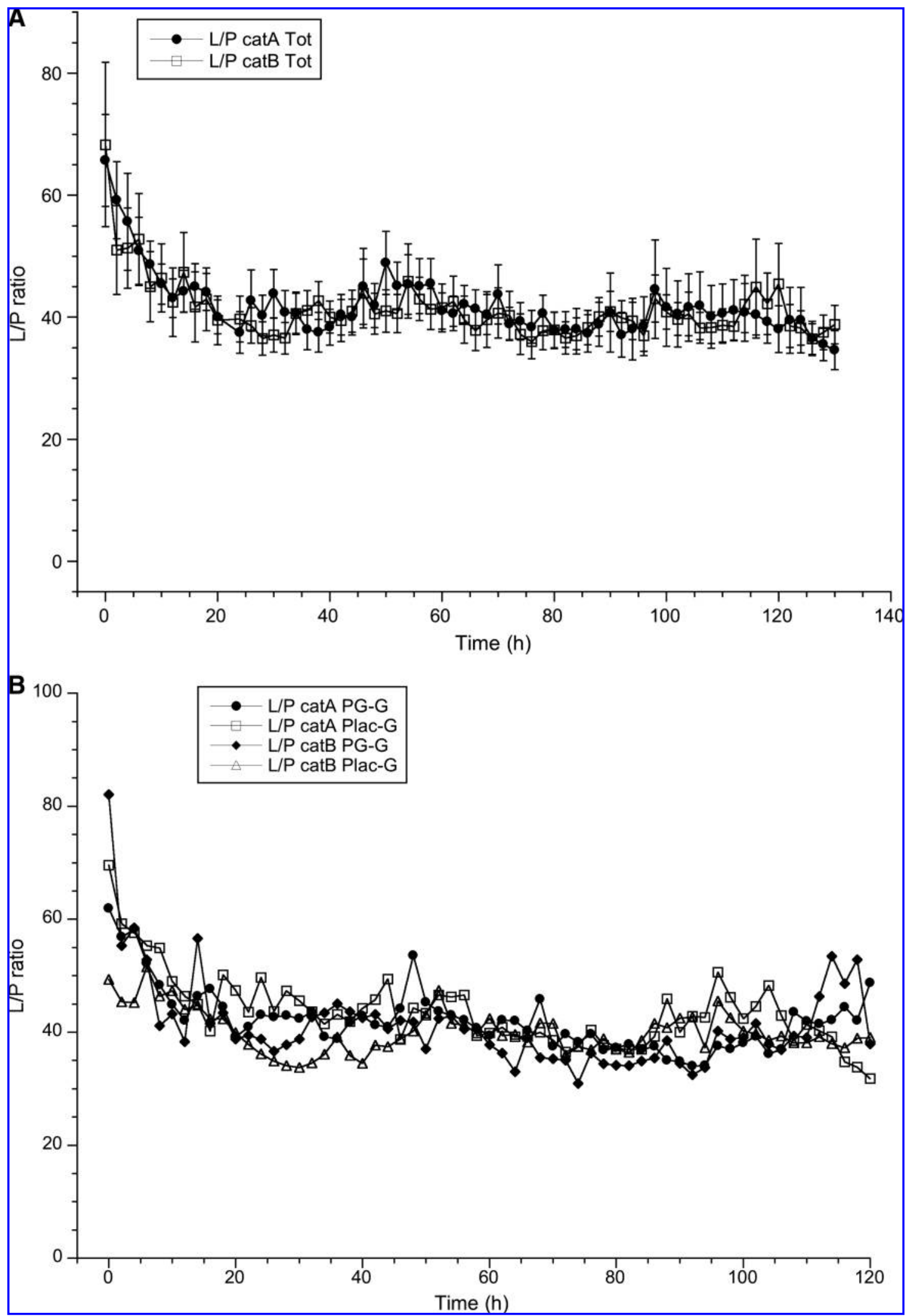

FIG. 5. (A) The temporal profile of the $\mathrm{L} / \mathrm{P}$ ratio for the whole material divided by brain microdialysis catheters (A and $\mathrm{B})$. Values are mean \pm sem. (B) The temporal profile of the L/P for the two treatment groups (PG-G and Plac-G) divided by brain microdialysis catheters (A and B). Values are mean. 
Table 3. Glucose (mmol/L) in 0-SAmple and after 24 h of Treatment with Test Drug

\begin{tabular}{|c|c|c|c|c|c|c|c|}
\hline \multirow[b]{2}{*}{ Time } & \multicolumn{3}{|c|}{ Prostacyclin group $(\mathrm{n}=23)$} & \multicolumn{3}{|c|}{ Placebo group $(\mathrm{n}=25)$} & \multirow[b]{2}{*}{ Significance } \\
\hline & A catheter & $B$ catheter & C catheter & A catheter & B catheter & C catheter & \\
\hline $\begin{array}{l}\text { 0-sample } \\
\quad \text { Mean } \pm \text { SEM }\end{array}$ & $2.5 \pm 0.6$ & $2.3 \pm 0.4$ & $4.3 \pm 0.6$ & $1.7 \pm 0.2$ & $1.8 \pm 0.3$ & $3.1 \pm 0.4$ & $\begin{array}{l}\text { A to } A \text { n.s. } \\
B \text { to } B \text { n.s. } \\
C \text { to } C \text { n.s. }\end{array}$ \\
\hline $\begin{array}{l}\text { 24h } \\
\quad \text { Mean } \pm \text { SEM }\end{array}$ & $2.1 \pm 0.4$ & $2.3 \pm 0.4$ & $5.0 \pm 0.5$ & $1.7 \pm 0.3$ & $1.6 \pm 0.2$ & $4.9 \pm 0.5$ & $\begin{array}{l}\text { A to A n.s. } \\
B \text { to } B \text { n.s. } \\
C \text { to } C \text { n.s. }\end{array}$ \\
\hline Significance & n.s. & n.s. & n.s. & n.s. & n.s. & $p<0.0005$ & \\
\hline
\end{tabular}

A catheter brain (worse side); B catheter brain (better side); C catheter adipose subcutaneous tissue; n.s., non-significant (unpaired Student's $t$-test between groups, paired Student's $t$-test within groups).

did not change our results concerning the effect of epoprostenol.

Interestingly, we did not observe a statistically significant difference in the results between the $\mathrm{A}$ catheter and the $\mathrm{B}$ catheter. It has been shown that there is a difference in the microdialysis results, depending on the catheter placement and in particular in relation to the most- or least-injured hemisphere (Stahl et al., 2001a, 2003; Bellander et al., 2004; Engstrom et al., 2005). The difficulty of designating better and worse sides is well illustrated with the subject in which the baseline L/P (470.6) in the B catheter (better side) by far exceeded the value on the worse side (59.1 in the A catheter). At $24 \mathrm{~h}$ the $\mathrm{L} / \mathrm{P}$ had decreased to 63.8 and 40.0 , respectively.

There was no significant difference in the brain glucose concentrations, neither between PG-G and Plac-G, nor between the baseline sample and the samples at $24 \mathrm{~h}$. The glucose levels were within the range considered normal, that is, about $2 \mathrm{mmol} / \mathrm{L}$ (Reinstrup et al., 2000; Schulz et al., 2000). The changes in glucose levels over time show the same pattern as that reported by other authors (Stahl et al., 2001a, 2001b; Lourido et al., 2002). There was no difference in the temporal profile of brain glucose in the PG-G and Plac-G or the catheters (A and B). Thus, no indirect signs of hypoperfusion or ischemia were observed. The observations of normal glucose levels and a L/P that, during the first $24 \mathrm{~h}$, declines and stabilizes in a normal range indicate that the treatment given seems to protect the subjects from secondary brain injuries. The elevated L/P cannot be taken as a sign of an irreversible ischemia but could perhaps be interpreted as a warning sign. This is supported by the normal glucose levels. The stable subcutaneous glucose concentration gives an indirect sign of a stable blood glucose concentration in the normoglycemic range.

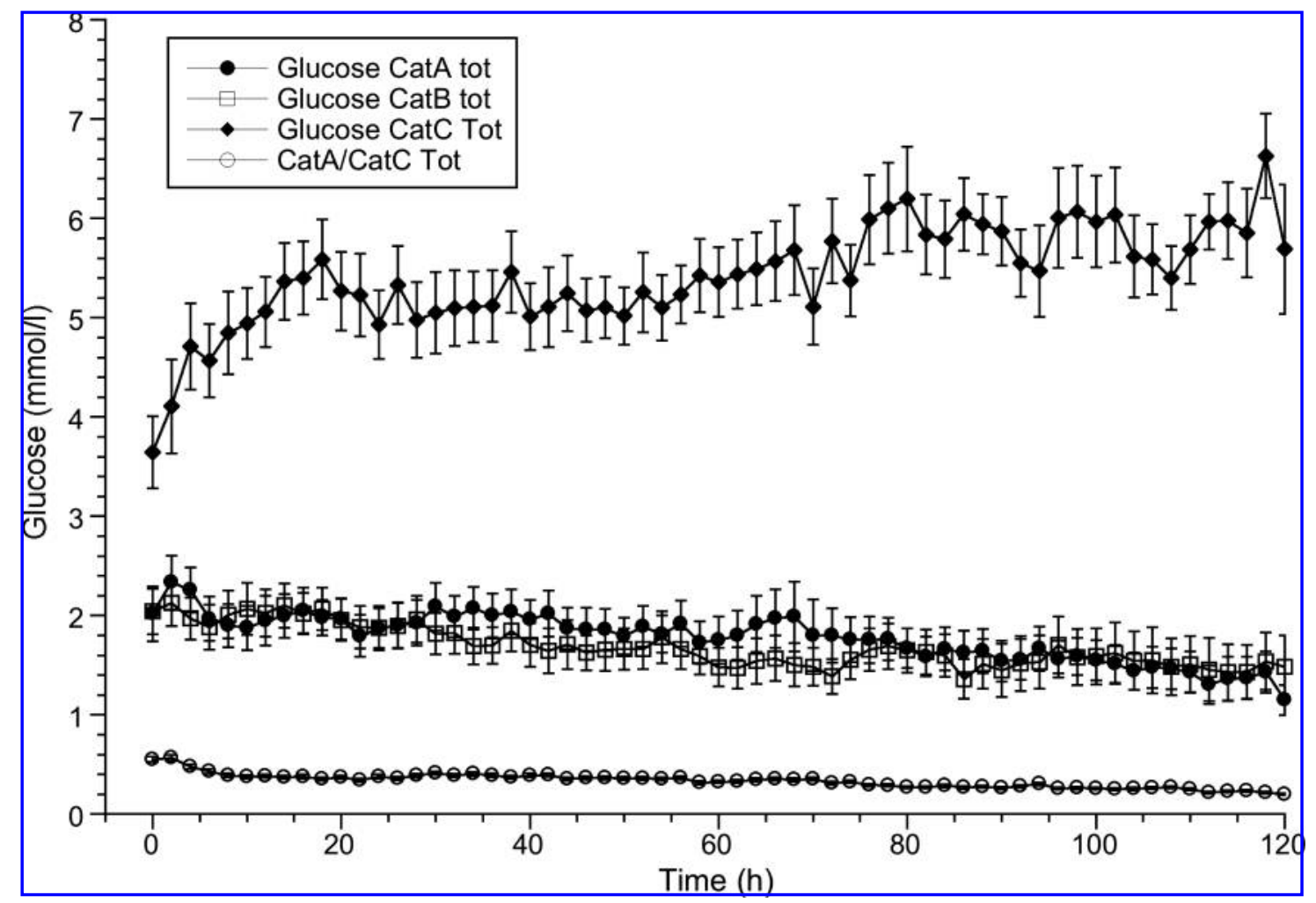

FIG. 6. The temporal profile of glucose concentration (mmol/L) for the two brain catheters (A and B), the subcutaneous catheter $(C)$, and the ratio between the catheters $A$ and $C$. Values are mean \pm sem. 


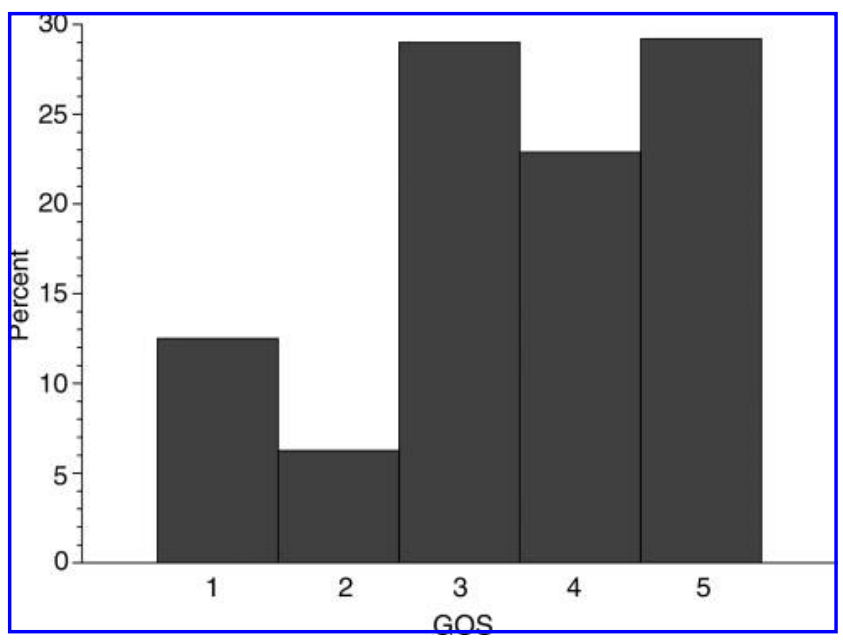

FIG. 7. Outcome as GOS in the total material.

The initial L/P has been suggested to be a surrogate endpoint for clinical outcome. We show that there is no statistically significant correlation between the initial $\mathrm{L} / \mathrm{P}$ and the clinical outcome measured as GOS at 3 months. Further, our data show that the initial $\mathrm{L} / \mathrm{P}$ is not a useable prognostic measure for the clinical outcome (GOS) in this cohort of subjects. The results also show the difficulty in using the primary $\mathrm{L} / \mathrm{P}$ as a divider between when to treat or not to treat.

Caution should be taken in interpreting microdialysis data, as the microtrauma after the insertion of the microdialysis probe can induce erroneous values. This is a problem that all microdialysis reports share, but few deal with. Unfortunately, many publications do not even mention when the first microdialysis sample is collected in relation to insertion. The consensus meeting on microdialysis in neurointensive care (Bellander et al., 2004) recommends an equilibration period of at least one hour. As our 0-sample is collected in the majority of cases between the second and fourth hours, we consider our equilibration period to be appropriate.

It has been argued that the placement of the catheters play a crucial role in the microdialysis results demonstrated. Indeed, a consensus on the placement of microdialysis catheters in the

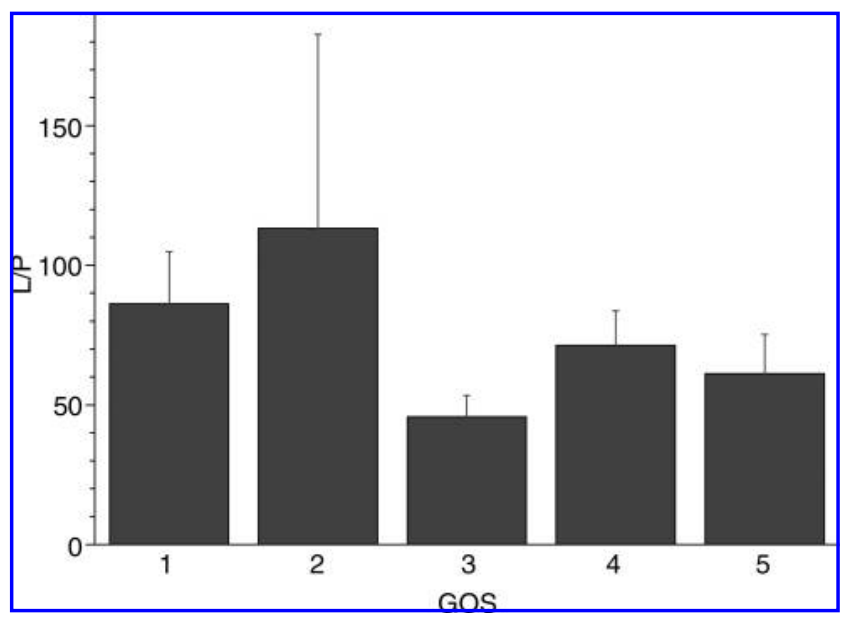

FIG. 8. Initial L/P in the A catheter to GOS at 3 months. Values are mean \pm sem. brain has been published (Hutchinson, 2002; Bellande et al., 2004). We have chosen to place the brain catheters in a standardized fashion, bilaterally and frontally. This is to our knowledge the most practical way of handling the insertion of microdialysis catheters in these severely ill subjects. If the method is to be used as a standard monitoring technique, it has to be reliable and easy to use, and the location of the catheters should not be the issue of reliability. One can argue that the measuring point should be in the so-called penumbra zone (Engstrom et al., 2005). There is no common definition of the penumbra zone, and the difficulty of defining the penumbra zone is seldom addressed. Further, it is important that the sampling site is not located in a contusion, as a large portion of this tissue is not salvageable. Furthermore, the pathophysiology of sTBI is a dynamic process; an area judged to be normal can over time turn into a area with a radiological lesion and an injured area can turn into a non-salvageable region. The only way to place the microdialysis catheters with high accuracy and in a pre-targeted volume is to do it by means of a stereotactical or neuronavigation supported procedure. This is, in our opinion, not practically feasible in these severely ill subjects and in a daily clinical practice.

Indeed, one can argue that the localization of the microdialysis catheters in the present study was not optimal in relation to the penumbra zone. We cannot exclude this possibility; the microdialysis results might be different with another catheter placement. This is a problem shared with many other publications and will be part of future studies.

We have earlier reported favorable outcomes in our sTBI subjects in the range of 60 to $70 \%$ and a mortality of approximately 15\% (Naredi et al., 2001; Wahlstrom et al., 2005; Olivecrona et al., 2007). In the present study we found favorable outcomes, assessed at 3 months after the trauma, in $52 \%$ of the subjects, with a mortality of $12.5 \%$. Two subjects died during treatment in the ICU, corresponding to an in-house mortality of $4.2 \%$. Subjects were treated in the ICU until they had a stable ICP of below $20 \mathrm{~mm} \mathrm{Hg}$, or died. Thus, $95.8 \%$ of the subjects with sTBI were discharged alive. The treatment used seems to prevent death in sTBI due to therapy-resistant ICP, as only two of the subjects died due to this reason. The treatment seems to yield a high number of subjects with favorable outcome after sTBI. The favorable outcome we report is lower as compared to our earlier reports. This is most probably due to the fact that the earlier published outcomes are reported after a later follow-up time. Furthermore, the patients in the present study were more severely injured as judged from the GCS at intubation and sedation compared to those in our previous studies (Naredi et al., 2001; Wahlstrom et al., 2005; Olivecrona et al., 2007). The high ISS and APACHE II scores also illustrate the severity of the injuries in the subjects. In most outcome studies of sTBI, patients with dilated non-reactive pupils and or GCS of 3 are excluded. We have chosen to accept all subjects irrespective of clinical status into the study as long as the subject presented an initial CPP of $10 \mathrm{~mm} \mathrm{Hg}$ or higher. If we exclude the subjects, with fixed, dilated pupils and/or GCS 3 from the study, the mortality would be $0 \%$. An independent study from the Umeå University Hospital using the local trauma bank confirmed that the mortality in subjects primarily admitted alive with a sTBI $(\mathrm{n}=10)$ to our hospital during one year (2001) was 0\% (Styrke et al., 2007). Most important is that a low mortality rate does not result in surviving vegetative subjects. We show that the 
number of vegetative subjects, in spite of the low mortality, is low. Irrespective of dichotomization, there was no difference in the outcome assessed as GOS between the PG-G and the Plac-G. We realize that it might be difficult to show any improvement in clinical outcome using a single new element, such as prostacyclin, as the outcome in the control group already is very good.

\section{Conclusions}

Epoprostenol at the dose of $0.5 \mathrm{ng} / \mathrm{kg} / \mathrm{min}$ had no influence on the brain L/P or brain glucose levels measured by microdialysis. In addition, no effect of prostacyclin on the clinical outcome was identified at 3 months. The present study does not exclude the possibility that prostacyclin in higher doses may be beneficial. The treatment protocol was followed and did not result in ischemic episodes in the brain. The initial $\mathrm{L} / \mathrm{P}$ did not prognosticate for clinical outcome. Microdialysis remains a valuable research tool, but in our opinion the findings are difficult to interpret in a clinical setting. Accordingly, to base treatment decisions on the findings is even more difficult.

\section{Author Disclosure Statement}

This study was supported by GlaxoSmithKline, Stockholm, Sweden, which supplied the hospital pharmacy with the active test drug.

\section{Acknowledgments}

We thank the staff at the neurosurgical department and intensive care unit of Umeå University, without whose kindness, interest, and dedicated work the study could not have been performed. A special thanks to our research nurses, Kristin Nyman and Anna-Lena Östlund, for their invaluable help and support in making this study possible. This study was financially supported by the Department of Clinical Neurosciences University Hospital Research Fund, Tore Nilsson Fund, Kempe Fund, Capio Research Fund, and Umeå University.

\section{References}

Agren-Wilsson, A., Eklund, A., Koskinen, L.O., Bergenheim, A.T., and Malm, J. (2005). Brain energy metabolism and intracranial pressure in idiopathic adult hydrocephalus syndrome. J. Neurol. Neurosurg. Psychiatry 76, 1088-1093.

Andrews, P.J., Sleeman, D.H., Statham, P.F., McQuatt, A., Corruble, V., Jones, P.A., Howells, T.P., and Macmillan, C.S. (2002). Predicting recovery in patients suffering from traumatic brain injury by using admission variables and physiological data: a comparison between decision tree analysis and logistic regression. J. Neurosurg. 97, 326-336.

Asgeirsson, B., Grande, P.O., and Nordstrom, C.H. (1994). A new therapy of post-trauma brain oedema based on haemodynamic principles for brain volume regulation. Intensive Care Med. 20, 260-267.

Bellander, B.M., Cantais, E., Enblad, P., Hutchinson, P., Nordstrom, C.H., Robertson, C., Sahuquillo, J., Smith, M., Stocchetti, N., Ungerstedt, U., Unterberg, A., and Olsen, N.V. (2004). Consensus meeting on microdialysis in neurointensive care. Intensive Care Med. 30, 2166-2169.

Bentzer, P., Holbeck, S., and Grande, P.O. (1999). Prostacyclin reduces microvascular fluid conductivity in cat skeletal mus- cle through opening of ATP-dependent potassium channels. J. Vasc. Res. 36, 516-523.

Bentzer, P., Kongstad, L., and Grande, P.O. (2001a). Capillary filtration coefficient is independent of number of perfused capillaries in cat skeletal muscle. Am. J. Physiol. Heart Circ. Physiol 280, H2697-2706.

Bentzer, P., Mattiasson, G., McIntosh, T.K., Wieloch, T., and Grande, P.O. (2001b). Infusion of prostacyclin following experimental brain injury in the rat reduces cortical lesion volume. J. Neurotrauma 18, 275-285.

Blebea, J., Cambria, R.A., DeFouw, D., Feinberg, R.N., Hobson, R.W., 2nd, and Duran, W.N. (1990). Iloprost attenuates the increased permeability in skeletal muscle after ischemia and reperfusion. J. Vasc. Surg. 12, 657-665; discussion 665-656.

Boullin, D.J., Bunting, S., Blaso, W.P., Hunt, T.M., and Moncada, S. (1979). Responses of human and baboon arteries to prostaglandin endoperoxides and biologically generated and synthetic prostacyclin: their relevance to cerebral arterial spasm in man. Br. J. Clin. Pharmacol. 7, 139-147.

Brandt, L., Ljunggren, B., Andersson, K.E., Hindfelt, B., and Uski, T. (1981). Effects of indomethacin and prostacyclin on isolated human pial arteries contracted by CSF from patients with aneurysmal SAH. J. Neurosurg. 55, 877-883.

Clifton, G. L., Miller, E.R., Choi, S.C., and Levin, H.S. (2002). Fluid thresholds and outcome from severe brain injury. Crit. Care Med. 30, 739-745.

Davies, M.G., and Hagen, P.O. (1993). The vascular endothelium. A new horizon. Ann. Surg. 218, 593-609.

Enblad, P., Valtysson, J., Andersson, J., Lilja, A., Valind, S., Antoni, G., Langstrom, B., Hillered, L., and Persson, L. (1996). Simultaneous intracerebral microdialysis and positron emission tomography in the detection of ischemia in patients with subarachnoid hemorrhage. J. Cereb. Blood Flow Metab. 16, 637-644.

Engstrom, M., Polito, A., Reinstrup, P., Romner, B., Ryding, E., Ungerstedt, U., and Nordstrom, C.H. (2005). Intracerebral microdialysis in severe brain trauma: the importance of catheter location. J. Neurosurg. 102, 460-469.

Erlansson, M., Bergqvist, D., Persson, N.H., and Svensjo, E. (1991). Modification of postischemic increase of leukocyte adhesion and vascular permeability in the hamster by Iloprost. Prostaglandins 41, 157-168.

Grande, P.O., Asgeirsson, B., and Nordstrom, C.H. (1997). Physiologic principles for volume regulation of a tissue enclosed in a rigid shell with application to the injured brain. J. Trauma 42, S23-31.

Grande, P.O., Moller, A.D., Nordstrom, C.H., and Ungerstedt, U. (2000). Low-dose prostacyclin in treatment of severe brain trauma evaluated with microdialysis and jugular bulb oxygen measurements. Acta Anaesthesiol. Scand. 44, 886-894.

Grande, P.O., Asgeirsson, B., and Nordstrom, C.H. (2002). Volume-targeted therapy of increased intracranial pressure: the Lund concept unifies surgical and non-surgical treatments. Acta Anaesthesiol. Scand. 46, 929-941.

Granholm, L., and Siesjo, B.K. (1969). The effects of hypercapnia and hypocapnia upon the cerebrospinal fluid lactate and pyruvate concentrations and upon the lactate, pyruvate, ATP, ADP, phosphocreatine and creatine concentrations of cat brain tissue. Acta Physiol. Scand. 75, 257-266.

Gryglewski, R.J., Dembinska-Kiec, A., and Korbut, R. (1978). A possible role of thromboxane A2 (TXA2) and prostacyclin (PGI2) in circulation. Acta Biol. Med. Ger. 37, 715-723.

Guidelines for the management of severe traumatic brain injury. IX. Cerebral perfusion thresholds. J. Neurotrauma 24 Suppl 1, S59-64. 
Hutchinson, P. (2002). Third International Satellite Conference on Neuro-Chemical Monitoring. Proposed guidelines for neurochemical monitoring. Acta Neurochir. Suppl 81, 341-342.

Jahr, J., and Grande, P.O. (1996). Prostacyclin counteracts the increase in capillary permeability induced by tumour necrosis factor-alpha. Intensive Care Med. 22, 1453-1460.

Jones, G., and Hurley, J.V. (1984). The effect of prostacyclin on the adhesion of leucocytes to injured vascular endothelium. J. Pathol. 142, 51-59.

Koskinen, L.O., and Olivecrona, M. (2005). Clinical experience with the intraparenchymal intracranial pressure monitoring Codman MicroSensor system. Neurosurgery 56, 693-698; discussion, 693-698.

Koskinen, L.O.D., Olivecrona, M., Rodling-Wahlstrom, M., and Naredi, S. (2009). Prostacyclin treatment normalizes the MCA flow velocity in nimodipine-resistant cerebral vasospasm after aneurysmal subarachnoid hemorrhage. A pilot study. Acta Neurochir. DOI 10.1007/S00701-009-0295-4. (Epub ahead of print.)

Lewis, P.J., and Dollery, C.T. (1983). Clinical pharmacology and potential of prostacyclin. Br. Med. Bull. 39, 281-284.

Lourido, J., Ederoth, P., Sundvall, N., Ungerstedt, U., and Nordstrom, C.H. (2002). Correlation between blood glucose concentration and glucose concentration in subcutaneous adipose tissue evaluated with microdialysis during intensive care. Scand. J. Clin. Lab. Invest. 62, 285-292.

Lundblad, C., Grande, P.O., and Bentzer, P. (2008). Increased cortical cell loss and prolonged hemodynamic depression after traumatic brain injury in mice lacking the IP receptor for prostacyclin. J. Cereb. Blood Flow Metab. 28, 367-376.

Mizuno-Yagyu, Y., Hashida, R., Mineo, C., Ikegami, S., Ohkuma, S., and Takano, T. (1987). Effect of PGI2 on transcellular transport of fluorescein dextran through an arterial endothelial monolayer. Biochem. Pharmacol. 36, 3809-3813.

Moller, A.D., and Grande, P.O. (1997). Low-dose prostacyclin has potent capillary permeability-reducing effect in cat skeletal muscle in vivo. Am. J. Physiol .273, H200-207.

Moller, A.D., and Grande, P.O. (1999a). Low-dose prostacyclin is superior to terbutaline and aminophylline in reducing capillary permeability in cat skeletal muscle in vivo. Crit. Care Med. 27, 130-136.

Moller, A.D., and Grande, P.O. (1999b). Role of prostacyclin and nitric oxide in regulation of basal microvascular hydraulic permeability in cat skeletal muscle. J. Vasc. Res. 36, 245-252.

Moncada, S., Gryglewski, R., Bunting, S., and Vane, J.R. (1976). An enzyme isolated from arteries transforms prostaglandin endoperoxides to an unstable substance that inhibits platelet aggregation. Nature 263, 663-665.

Moncada, S., and Amezcua, J.L. (1979). Prostacyclin, thromboxane A2 interactions in haemostasis and thrombosis. Hae$\underline{\text { mostasis } 8,252-265 .}$

Moncada, S., and Vane, J.R. (1979a). Arachidonic acid metabolites and the interactions between platelets and blood-vessel walls. N. Engl. J. Med. 300, 1142-1147.

Moncada, S., and Vane, J.R. (1979b). The role of prostacyclin in vascular tissue. Fed. Proc. 38, 66-71.

Morel, N.M., Petruzzo, P.P., Hechtman, H.B., and Shepro, D. (1990). Inflammatory agonists that increase microvascular permeability in vivo stimulate cultured pulmonary microvessel endothelial cell contraction. Inflammation 14, 571-583.

Naredi, S., Olivecrona, M., Lindgren, C., Ostlund, A.L., Grande, P. O., and Koskinen, L.O. (2001). An outcome study of severe traumatic head injury using the "Lund therapy" with lowdose prostacyclin. Acta Anaesthesiol. Scand. 45, 402-406.
Olivecrona, M., Rodling-Wahlstrom, M., Naredi, S., and Koskinen, L.O. (2007). Effective ICP reduction by decompressive craniectomy in patients with severe traumatic brain injury treated by an ICP-targeted therapy. J. Neurotrauma 24, 927-935.

Persson, L., and Hillered, L. (1992). Chemical monitoring of neurosurgical intensive care patients using intracerebral microdialysis. J. Neurosurg. 76, 72-80.

Reinstrup, P., Stahl, N., Mellergard, P., Uski, T., Ungerstedt, U., and Nordstrom, C.H. (2000). Intracerebral microdialysis in clinical practice: baseline values for chemical markers during wakefulness, anesthesia, and neurosurgery. Neurosurgery 47, 701-709; discussion 709-710.

Ritter, J.M., Barrow, S.E., Blair, I.A., and Dollery, C.T. (1983). Release of prostacyclin in vivo and its role in man. Lancet 1 , 317-319.

Schulz, M.K., Wang, L.P., Tange, M., and Bjerre, P. (2000). Cerebral microdialysis monitoring: determination of normal and ischemic cerebral metabolisms in patients with aneurysmal subarachnoid hemorrhage. J. Neurosurg. 93, 808-814.

Seifert, V., Stolke, D., Kaever, V., and Dietz, H. (1987). Arachidonic acid metabolism following aneurysm rupture. Evaluation of cerebrospinal fluid and serum concentration of 6-keto-prostaglandin F1 alpha and thromboxane B2 in patients with subarachnoid hemorrhage. Surg. Neurol. 27, 243-252.

Stahl, N., Mellergard, P., Hallstrom, A., Ungerstedt, U., and Nordstrom, C.H. (2001a). Intracerebral microdialysis and bedside biochemical analysis in patients with fatal traumatic brain lesions. Acta Anaesthesiol. Scand. 45, 977-985.

Stahl, N., Ungerstedt, U., and Nordstrom, C.H. (2001b). Brain energy metabolism during controlled reduction of cerebral perfusion pressure in severe head injuries. Intensive Care Med. 27, 1215-1223.

Stahl, N., Schalen, W., Ungerstedt, U., and Nordstrom, C.H. (2003). Bedside biochemical monitoring of the penumbra zone surrounding an evacuated acute subdural haematoma. Acta Neurol. Scand. 108, 211-215.

Styrke, J., Stalnacke, B.M., Sojka, P., and Bjornstig, U. (2007). Traumatic brain injuries in a well-defined population: epidemiological aspects and severity. J. Neurotrauma 24, 1425-1436.

Wahlstrom, M.R., Olivecrona, M., Koskinen, L.O., Rydenhag, B., and Naredi, S. (2005). Severe traumatic brain injury in pediatric patients: treatment and outcome using an intracranial pressure targeted therapy-the Lund concept. Intensive Care Med. 31, 832-839.

Vespa, P., Bergsneider, M., Hattori, N., Wu, H.M., Huang, S.C., Martin, N.A., Glenn, T.C., McArthur, D.L., and Hovda, D.A. (2005). Metabolic crisis without brain ischemia is common after traumatic brain injury: a combined microdialysis and positron emission tomography study. I. Cereb. Blood Flow Metab. 25, 763-774.

Vespa, P.M., O'Phelan, K., McArthur, D., Miller, C., Eliseo, M., Hirt, D., Glenn, T., and Hovda, D.A. (2007). Pericontusional brain tissue exhibits persistent elevation of lactate/pyruvate ratio independent of cerebral perfusion pressure. Crit. Care Med. 35, 1153-1160.

Address correspondence to: Lars-Owe D. Koskinen, M.D., Ph.D. Department of Neurosurgery University Hospital SE 90185 Umeå Sweden

E-mail: Lars-Owe.Koskinen@neuro.umu.se 